\title{
Early Frameshift Mutation in PIGA Identified in a Large XLID Family Without Neonatal Lethality
}

\author{
Stefanie Belet, ${ }^{1,2}$ Nathalie Fieremans, ${ }^{1,2}$ Xuan Yuan, ${ }^{3}$ Hilde Van Esch, ${ }^{4}$ Jelle Verbeeck ${ }^{1,2}$ Zhaohui Ye, ${ }^{3}$ Linzhao Cheng, ${ }^{3}$ \\ Brett R. Brodsky, ${ }^{3}$ Hao Hu, ${ }^{5}$ Vera M. Kalscheuer, ${ }^{5}$ Robert A. Brodsky, ${ }^{3}$ and Guy Froyen ${ }^{1,2 *}$ \\ ${ }^{1}$ Human Genome Laboratory, VIB Center for the Biology of Disease, Leuven, Belgium; ${ }^{2}$ Human Genome Laboratory, Department of Human \\ Genetics, KU Leuven, Leuven, Belgium; ${ }^{3}$ Division of Hematology, Department of Medicine, John Hopkins University, Baltimore, Maryland; \\ ${ }^{4}$ University Hospitals Leuven, Center for Human Genetics, KU Leuven, Leuven, Belgium; ${ }^{5}$ Max Planck Institute for Molecular Genetics, Department \\ of Human Molecular Genetics, Berlin, Germany
}

Communicated by Maria Rita Passos-Bueno

Received 12 September 2013; accepted revised manuscript 12 December 2013.

Published online 19 December 2013 in Wiley Online Library (www.wiley.com/humanmutation). DOI: 10.1002/humu.22498

\begin{abstract}
The phosphatidylinositol glycan class A (PIGA) protein is a member of the glycosylphosphatidylinositol anchor pathway. Germline mutations in PIGA located at $\mathrm{Xp22.2}$ are thought to be lethal in males. However, a nonsense mutation in the last coding exon was recently described in two brothers with multiple congenital anomalies-hypotonia-seizures syndrome 2 (MCAHS2) who survived through birth likely because of the hypomorphic nature of the truncated protein, but died in their first weeks of life. Here, we report on a frameshift mutation early in the PIGA cDNA (c.76dupT; p.Y26Lfs*3) that cosegregates with the disease in a large family diagnosed with a severe syndromic form of X-linked intellectual disability. Unexpectedly, CD59 surface expression suggested the production of a shorter PIGA protein with residual functionality. We provide evidence that the second methionine at position 37 may be used for the translation of a 36 amino acids shorter PIGA. Complementation assays confirmed that this shorter PIGA cDNA was able to partially rescue the surface expression of CD59 in a PIGAnull cell line. Taken together, our data strongly suggest that the early frameshift mutation in PIGA produces a truncated hypomorph, which is sufficient to rescue the lethality in males but not the MCAHS2-like phenotype. Hum Mutat 35:350-355, 2014. (C) 2013 Wiley Periodicals, Inc.
\end{abstract}

KEY WORDS: PIGA; GPI-anchor; intellectual disability; frameshift; start codon

\footnotetext{
* Correspondence to: Guy Froyen, Human Genome Laboratory, Department of Human Genetics, KU Leuven, B-3000 Leuven, Belgium. E-mail: guy.froyen@med.kuleuven.be

Contract grant sponsors: University of Leuven (Leuven, Belgium) (G0A/12/015); the Interuniversity Attraction Poles' program (P7/43: Belgian Medical Genomics Initiative; BeMGI) from the Belgian Government; the National Institute of Health (P01 CA70970); the German Ministry of Education and Research through the MRNET; the European Union Framework Programme 7 (241995).
}

\section{Introduction}

The extensive search for genes involved in X chromosome-linked intellectual disability (XLID), which affects $0.3 \%$ of the population, already revealed about 90 XLID genes for which their proteins are involved in many different pathways [Gécz et al., 2009; Ropers, 2010]. However, at least half of the XLID families remain unsolved. Today, next generation sequencing allows for fast high-throughput detection of mutations in many different diseases including XLID.

Glycosylphosphatidylinositol (GPI) is synthesized and transferred to proteins in the membrane of the endoplasmic reticulum. In mammals, more than 20 proteins are involved in this process and at least 150 proteins carry this GPI sorting moiety [Fujita and Kinoshita, 2012]. The $16 \mathrm{~kb}$ long PIGA (MIM \#311770) located at $\mathrm{Xp} 22.2$, encodes a protein that is required for the first step of GPI-anchor biosynthesis [Brodsky, 2008]. Somatic mutations in PIGA were first described to be causal for paroxysmal nocturnal hemoglobinuria $(\mathrm{PNH})$, which is an uncommon acquired hemolytic anemia (MIM \#300818) [Takeda et al., 1993]. Clonal expansion of hematopoietic cells with mutations in PIGA result in complementmediated lysis of PNH erythrocytes due to loss of the protecting cell surface GPI-anchor proteins (GPI-AP) CD55 and CD59 [Brodsky, 2008]. Almost all PIGA mutations are unique, indicative for their somatic nature. Germline loss-of-function mutations were thought to be embryonically lethal because they had not been detected [Rosse, 1993]. Indeed, the generation of a Piga knockout mouse was not successful while Piga-deficient mice were only viable with very low-grade mosaicism [Kawagoe et al., 1996]. Germline mutations in other members of the GPI-anchor glycosylation family have been described to be associated with severe syndromes that often include hyperphosphatasia, seizures, hypotonia, and neurological symptoms. Compound heterozygous mutations in PIGL (MIM \#605947) result in CHIME syndrome (MIM \#280000) [ $\mathrm{Ng}$ et al., 2012], whereas in PIGN (MIM \#606097) they cause multiple congenital anomalies-hypotonia-seizures syndrome 1 (MCAHS1; MIM \#614080) [Maydan et al., 2011]. A homozygous promoter variation in PIGM (MIM \#610273) leads to a clinical phenotype that includes portal venous thrombosis and absence seizures (MIM \#610293) [Almeida et al., 2006]. Homozygous or compound heterozygous mutations in PIGV (MIM \#610274) [Krawitz et al., 2010] as well as compound heterozygous mutations in PIGO (MIM \#614730) [Krawitz et al., 2012] were detected to cause hyperphosphatasia with mental retardation syndrome 1 (HPMRS1; MIM \#239300) and -2 (HPMRS2; MIM \#614749), respectively. Although complete 
absence of PIGA is thought to be embryonically lethal, a nonsense mutation in the last coding exon has recently been reported in two newborn brothers suffering from MCAHS2 (MIM \#300868) [Johnston et al., 2012]. They demonstrated that a PIGA hypomorph allows survival past the embryonic stage. Next to mutations in these ERlocalized proteins, missense mutations in PGAP2, which is involved in fatty acid GPI-anchor remodeling in the Golgi, have recently been reported in patients with severe developmental delay and elevated serum alkaline phosphatase activity [Hansen et al., 2013; Krawitz et al., 2013]. All mutations identified in this GPI-anchor pathway result in reduced functional activity but no complete loss-of-function has been described for any of these proteins.

Here, we describe the identification of an insertion mutation in PIGA resulting in an early frameshift (p.Y26Lfs*3) that was expected to cause lethality in males from a large family. However, normal CD59 surface expression in the patient suggests the production of a truncated protein with sufficient residual activity to survive into adulthood. We demonstrated that a shorter PIGA starting from the second methionine indeed acts as a hypomorph, which could explain the clinical features in these males. As their clinical characteristics are less severe than those reported for MCAHS2 [Johnston et al., 2012], we define it here as the MCAHS2-like syndrome.

\section{Materials and Methods}

\section{Ethics Statements}

The protocol was approved by the Institutional Review Board of the University Hospitals Leuven, and informed consent was obtained from the parents of the affected patients and their healthy family members. DNA was extracted from peripheral blood using standard procedures.

\section{Chromosome Exome Sequencing and Validation}

Detailed information will be published elsewhere (Kalscheuer et al., unpublished). Briefly, X chromosome exome enrichment was performed on sequencing libraries using the Agilent SureSelect Human X Chromosome Kit (Agilent Technologies, Palo Alto, CA). Single-end deep sequencing was performed on the Genome Analyzer GAIIx (Illumina, San Diego, CA). Reads were mapped to the human reference genome based on UCSC March 2006 (Hg18; http://genome.ucsc.edu/). The DNA mutation numbering was based on CDNA sequence NM_002641.3. The insertion frameshift variant in PIGA was confirmed on another DNA sample of the patient by regular Sanger sequencing on an ABI3500xl sequence analyzer (Life Technologies, Foster City, CA) as was the cosegregation analysis. Primer sequences of this study are provided in Supp. Table S1.

\section{Expression Analysis by PCR and qPCR}

Total RNA was extracted from mouse brain, heart, liver, and blood using standard procedures, or purchased for the same human tissues (Life Technologies). Total RNA was also extracted from EBV-PBLs derived from the proband of family L024 as well as controls. After cDNA synthesis, regular PCR was done with primer pairs PIGA$\mathrm{a} / \mathrm{c}$ and PIGA-b/c to check for the different isoforms in EBV-PBLs. For quantitative analyses, qPCR was performed with the SYBRgreen method on an LC480 system (Roche, Basel, Switzerland) as previously described [Vandewalle et al., 2009], using PIGA primer pairs in exon 2 and 6 for the human and mouse tissue samples. The housekeeping gene GUSB/Gusb was used for normalization. Primer sequences of this study are provided in Supp. Table S1.

\section{CD59 Complementation Assay}

An EBV-PBL cell line from the proband, a PNH patient and three control individuals as well as a PIGA-null TF1 cell line were cultured in DMEM medium supplemented with $10 \%$ fetal calf serum and $1 \%$ penicillin/streptomycin. Surface expression of CD59 was performed by FACS analysis using the anti-CD59 antibody with FLAER adjustment as described previously [Brodsky et al., 2000; Sutherland et al., 2009]. For the complementation assay of an Nterminal truncated PIGA, we cloned the PIGA-M37cDNA construct in the piggyBac-based vector PB-CAG [Zou et al., 2012], to yield PB-PIGA-M37(109-1455). Plasmid constructs were confirmed by sequencing. Electroporation of 1,2 , and $5 \mu \mathrm{g}$ of this truncated or the full length wild-type (wt) construct, PB-PIGA-wt(1-1455) carrying the PIGA-wt cDNA (available in the lab), together with a second vector expressing an improved transposase gene [Yusa et al., 2011], into PIGA-null TF1 cells was done using a 4D-Amaxa Nucleofector system (Lonza, Basel, Switzerland) as described previously [Savage et al., 2009]. Two weeks after puromycin $(10 \mu \mathrm{g} / \mathrm{ml})$ selection for stable clones, cells were stained with anti-CD59 monoclonal antibody or FLAER followed by FACS Calibur ${ }^{\mathrm{TM}}$ flow cytometry (Becton Dickinson, Franklin Lakes, NJ). Data analysis was performed using FlowJo software (Tree Star, Ashland, OR). The TF1 cell line without a PIGA mutation was used as a positive control.

\section{Results}

\section{Identification of a PIGA Variant in L024}

L024 is a large Belgian family (Fig. 1) diagnosed with presumed X-linked infantile spasm syndrome (MIM \#308350) in five affected males suffering from profound retardation, axial hypotonia, epileptic seizures, and hypsarrhythmia. This family has been described previously by Claes et al. (1997) as family B. Of special note is that none of the patients suffered from any signs of PNH. Multipoint linkage analysis revealed significant linkage to Xpter - Xp11.4 (LOD 2.36) in which PIGA resides. Previously, all known XLID genes located in this interval had been sequenced without finding a potential causal variant [de Brouwer et al., 2007]. Also, karyotyping and $\mathrm{X}$ chromosome-specific array-CGH were normal.

We applied chromosome X-specific exome sequencing on DNA from probands of unsolved families as part of a large screen on $>400$ idiopathic XLID families (unpublished). In the linkage interval, 148 RefSeq protein coding genes were located and the reads covered the targeted regions by $96 \%$ with an average fold of $92 \times$. After filtering of all variants against publicly available data including the 1000 Genomes project (http://browser.1000genomes.org/index.html), dbSNP135 (http://www.ncbi.nlm.nih.gov/SNP/), and the Exome Variant Server (EVS: http://evs.gs.washington.edu/EVS/), as well as against our in-house database, four novel variants remained. The splice mutation in HS6ST2 was not considered harmful since truncating mutations are reported in normal male individuals (EVS). As the missense variants in RBM3 and RLIM did not segregate with the disease in the family, a single potential causal variant remained in the proband (IV.2) of family L024. It consisted of a one base (T) insertion at position ChrX:15,349,979 (complement strand; UCSC Hg19; http://genome.ucsc.edu) located in the coding sequence of PIGA (c.76dupT; NM_002641.3). The T insertion, confirmed by Sanger sequencing, resulted in a frameshift that generates a stop 


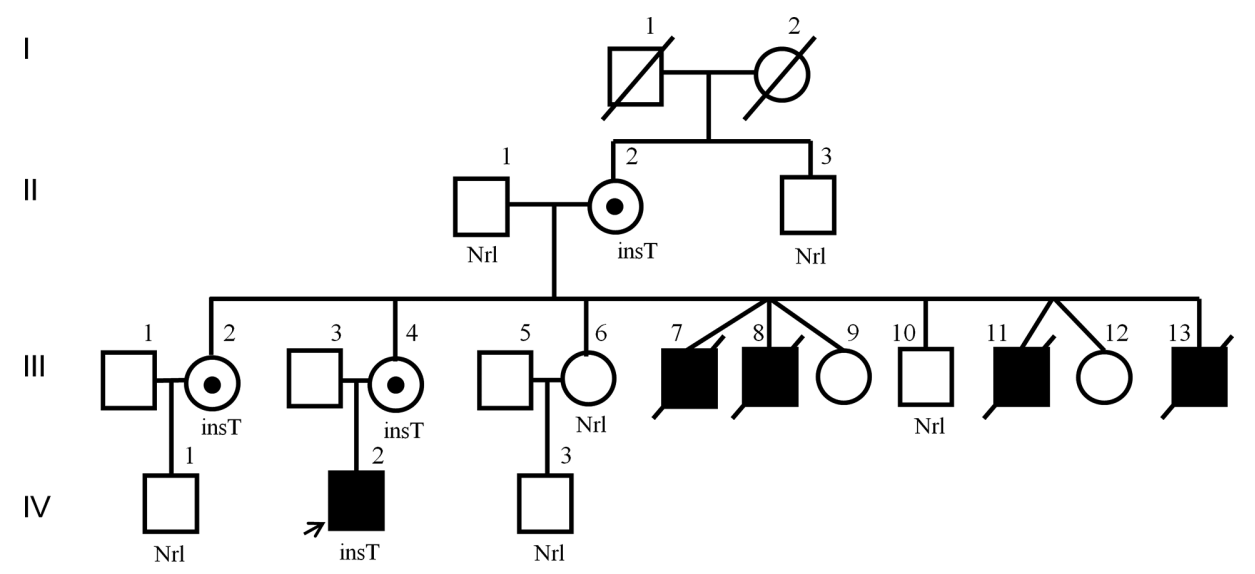

Figure 1. Pedigree of the L024 family. The affected boy IV.2 from whom the cell line was obtained, is indicated by the arrow. His four affected maternal uncles died and no DNA is available. The individuals that could be tested are indicated as carrying the apparent deleterious T insertion in PIGA (insT) or not (Nrl).

codon after amino acid (AA) 28 (p.Y26Lfs*3). Cosegregation analysis demonstrated that the PIGA variant was inherited from his healthy carrier mother (III.4). We also observed this T insertion in the unaffected grandmother (II.2) and maternal aunt (III.2), but not in the four healthy males (II.3, III.10, IV.1, IV.3) of the family. DNA was unavailable from the other affected males III.7, III.8, III.11, and III.13, who died at ages $1.5,21,18$, and 5 years, respectively, due to respiratory infections or prolonged status epilepticus, inherent to their clinical characteristics. The proband (IV.2) currently is 24 years old. This variant is present in the LOVD database (www.lovd.nl/PIGA) with number 0006897.

\section{Expression Analysis of PIGA Isoforms}

In order to check whether the mutation resides within the most commonly used PIGA isoforms, we performed qualitative and quantitative cDNA analysis in both man and mouse. In both species, this gene locates on the $\mathrm{X}$ chromosome and has a highly similar gene structure harboring 6 exons. In human, four isoforms are predicted, which only differ in the extent of (parts of) exon 2 (Supp. Fig. S1A). We confirmed the presence of these four isoforms in human cDNA samples derived from Epstein-Barr virus-transfected peripheral blood lymphocyte (EBV-PBLs) RNA, including the sample from the affected male of family L024 (Supp. Fig. S1B), demonstrating that the frameshift mutation does not affect the production of any of these transcripts. From these isoforms, two predicted coding transcripts were deduced, which only differ in their N-terminal parts (Supp. Fig. S1A). The main human coding isoform contains $484 \mathrm{AA}$ (485 AA in mouse) and has its start early in exon 2, followed by exons $3,4,5$, and 6 . The second predicted human coding isoform starts in exon 1 but skips exon 2 thereby producing a hypothetical protein of $250 \mathrm{AA}$ (264 AA in the mouse). Therefore, the germline predicted frameshift mutation early in exon 2 would be viable in our patient if the short isoform, which does not contain exon 2, would preferentially be expressed in cells from the hematopoietic system and thus would not affect cell surface expression in blood cells, precluding PNH. To test this hypothesis, we checked for the usage of both coding transcripts in cDNA obtained from mouse and human brain, heart, liver, and blood RNA samples. Relative quantification of the two coding isoforms was performed by qPCR using primer sets within exon 2, which only detects the long isoform, or within exon 6 , detecting both the long and short coding isoforms. The dif-

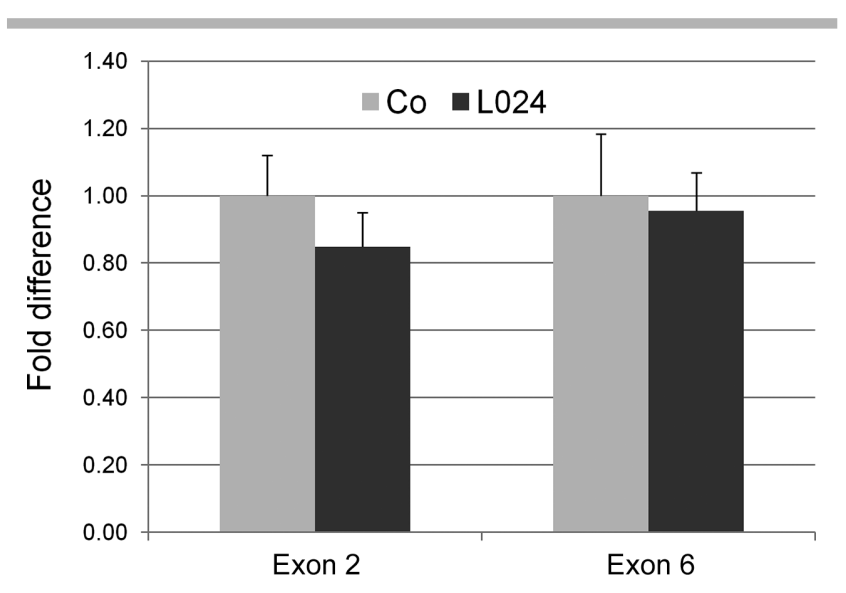

Figure 2. PIGA mRNA expression analysis in family L024 and in controls. Relative quantitation of mRNA expression by qPCR in EBV-PBLs from the affected individual (L024) and four control males (Co). qPCR primer pairs in exon 2 (long isoform) and exon 6 (long and short isoforms) were used. Fold difference in expression is given relative to the mean of the controls. Standard deviations from three independent assays are provided.

ference in expression levels obtained for both exons can thus be used as a measure for the preferential usage of either of both isoforms. Our data clearly show that indeed, most transcripts carry exon 2 in both human and mouse brain and blood samples, since the ratios obtained were always close to 1.00 (Supp. Fig. S2). Both noncoding isoforms appear to be expressed in our patient at physiological levels as well (Supp. Fig. S1B). To check whether the mutation would affect the amount of expressed PIGA mRNA, we quantified their levels by qPCR on total RNA extracted from EBV-PBLs from the proband IV. 2 and male controls as previously described [Vandewalle et al., 2009], using qPCR primer sets in exon 2 as well as exon 6. After normalization to GUSB, we did not detect altered PIGA expression in our patient (Fig. 2).

\section{CD59 Surface Expression and Complementation}

As no reliable antibody to human PIGA exists, we performed a functional assay to check for cell surface expression of CD59 by FACS analysis using the anti-CD59 antibody with FLAER adjustment. 
A

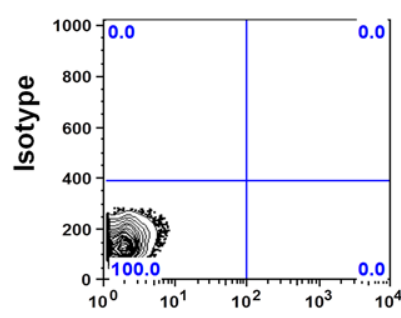

CD59 APC

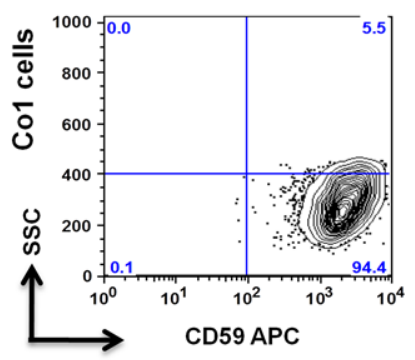

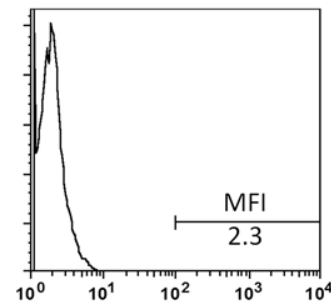

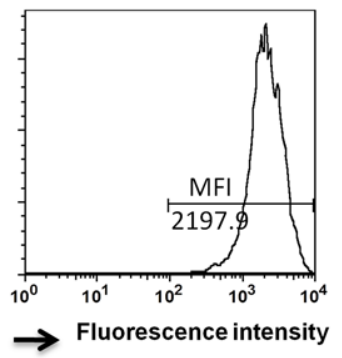

B

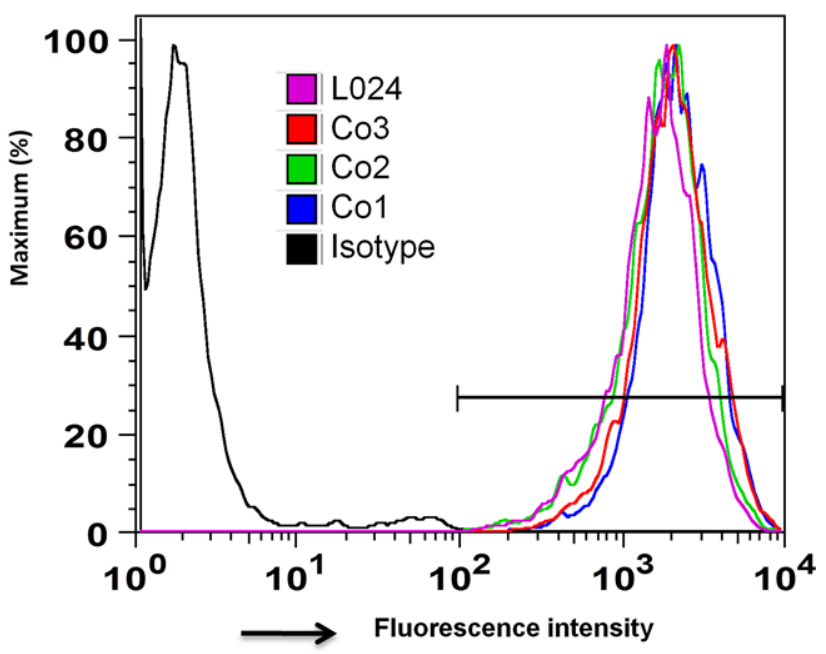

Figure 3. CD59 surface expression analysis in cells from L024 and controls. Flow cytometry on EBV-PBLs from patient (L024) and three control males (Co) stained with anti-CD59 Ab. A: Contour plot of flow cytometric analysis (left) and a histogram plot analysis of CD59 expression (right). MFI is the mean of fluorescence intensity of CD59 expression. Isotype control (top) and Co1 cells (bottom). B: Overlay plots of CD59 surface expression of Co1-3 and L024. Values for the experimental samples were based upon setting the baseline value for the isotype control.

Interestingly, the EBV-PBL cell line from the proband of L024 showed CD59 surface expression well within the normal range of the controls (Fig. 3). Complete absence was noted in a control EBV-PBL cell line derived from a PNH patient. These data clearly demonstrate that the early frameshift mutation in exon 2 does not affect GPI-AP surface expression strongly indicating that at least the first $25 \mathrm{AA}$ are not essential for a fully functional PIGA protein. Therefore, we tested the possibility that the second methionine located at position 37 (M37) would be used as the alternative start codon thereby generating an $\mathrm{N}$-terminal truncated PIGA protein. Additional support for that hypothesis comes from its evolutionary amino-acid conservation. The PIGA protein sequence is highly conserved up to yeast but always shows the poorest conservation in the first $31 \mathrm{AA}$. As an example, comparison of mouse and human PIGA, performed by BLS2seq (http://blast.ncbi.nlm.nih.gov/Blast.cgi), is shown in Supp. Figure S3 and indicates that this $\mathrm{N}$-terminal part does not share a common function between species or that it is not crucially important.

To test whether the truncated PIGA-M37 was functionally active, we generated constructs for expression of PIGA-M37(109-1455) and PIGA-wt(1-1455) (Fig. 4A). Electroporation of 1, 2, and $5 \mu \mathrm{g}$ of both vectors into PIGA-null TF1 cells, followed by puromycin selection yielded stable clones that were stained with anti-CD59 antibody or FLAER followed by FACS. The percentage and mean fluorescent intensity (MFI) data from three independent assays clearly demonstrated that the PIGA-M37(109-1455) construct partially complements the cell surface expression of CD59 as well as other GPI-APs (measured by FLAER) when compared with the PIGAwt(1-1455) construct (Fig. 4B). While transfection of PIGA-null TF1 cells with $1 \mu \mathrm{g}$ of PB-PIGA-wt(1-1455) was able to fully restore GPI-anchor surface expression with very similar MFI values as the wild-type TF1 cells (data not shown), even $5 \mu \mathrm{g}$ of PB-PIGAM37(109-1455) was not sufficient for complete restoration. These data confirm that the production of an N-terminal 36 AA shorter PIGA protein could act as a hypomorph for GPI-AP cell surface expression.

\section{Discussion}

We report on a frameshift insertion mutation in PIGA that was predicted to result in complete absence of this protein causing the severe hematological condition $\mathrm{PNH}$, which however was absent in the mutation-carrying male patients. We first demonstrated that the long PIGA isoform including exon 2 is the main transcript in all tested tissues. Indeed, the usage of an exon 2-carrying transcript in blood is in agreement with the identification of PNH-related frameshift and nonsense mutations in this exon [Yamada et al., 1995; Nafa et al., 1998; Johnson and Hillmen, 2002]. The expression of both predicted noncoding transcripts that have alternative splice sites within exon 2, did not seem to be affected. No function has yet been described for these presumed transcripts [Bessler et al., 1994].

Deleterious PIGA germline mutations were predicted to be embryonically lethal, supported by the Piga knockout mouse [Kawagoe et al., 1996]. Moreover, skewing and somatic cell selection has been reported to rescue Piga mutation-carrying female mice from lethality [Keller et al., 1999]. Recently however, the first germline PIGA mutation (p.R412X) has been reported in a family with MCAHS2. The three affected males harboring this nonsense mutation developed to term but died 4-11 weeks postnatally due to pneumonia, respiratory failure, or stroke [Johnston et al., 2012]. Since this nonsense mutation located in the last exon (exon 6) of PIGA, it was suggested not to be subjected to nonsense-mediated mRNA decay producing a truncated protein that lacks the C-terminal $73 \mathrm{AA}$. Indeed, a CD59 complementation assay demonstrated residual activity from the truncated PIGA, which precluded prenatal lethality in that family. In our family, the frameshift insertion mutation early in PIGA surprisingly did not show any change in CD59 surface expression in lymphocytes from the proband, which seems to indicate that hypomorphic germline mutations in the GPI anchor pathway is more conspicuous on granulocytes. Subtle to nonexistent differences in GPI-AP expression on lymphocytes and red blood cells have been previously reported [Almeida et al., 2006; Hansen et al., 2013]. In any case, these data are in line with a potential reinitiation of 
A

1

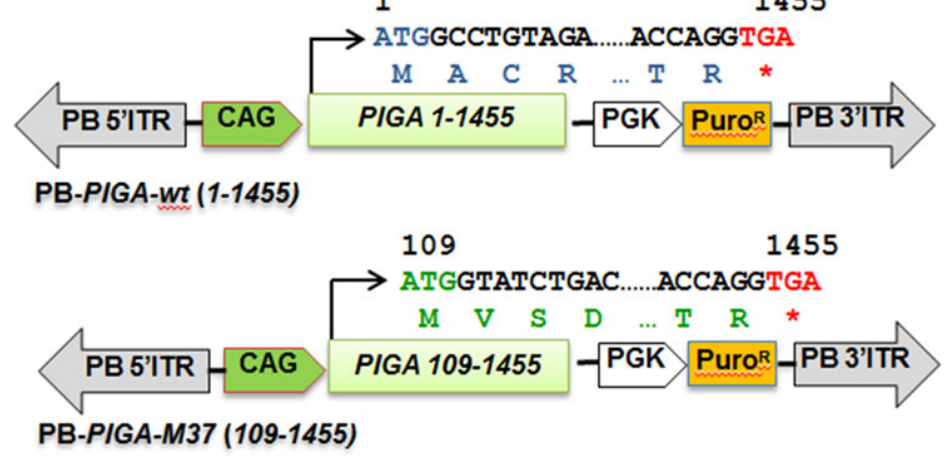

B
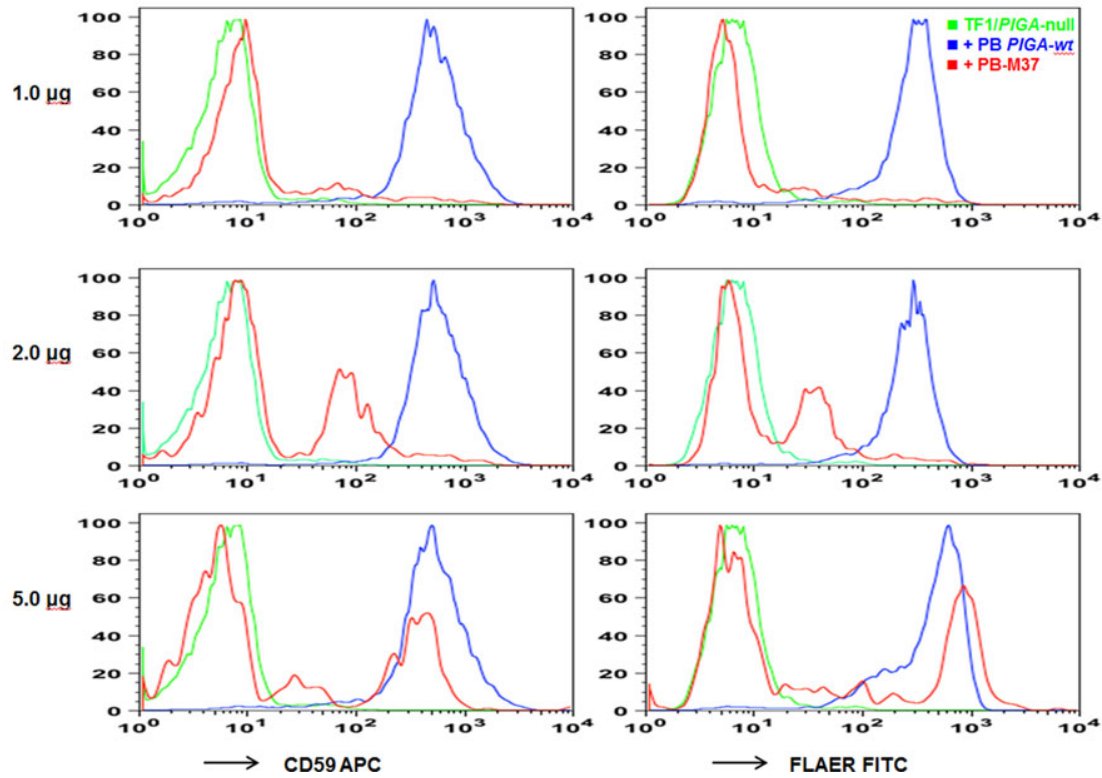

Figure 4. Complementation assay for CD59 surface expression and FLAER. A: Schematic representation of plasmids for the wild-type PIGA cDNA (PB-PIGA-wt(1-1455)) and truncated PIGA cDNA coding for a protein starting at methionine 37 (PB-PIGA-M37(109-1455)). B: PIGA-null TF1 cells were transfected with different amounts of PIGA-wt and PIGA-M37 cDNA plasmids as indicated on the left. After selection with puromycin, cells were stained with anti-CD59 antibody (left panels) or FITC-conjugated FLAER (right panels) and analyzed by FACS. Plots show mean fluorescence intensity (MFI) for the TF1 PIGA-null cells (indicated in green), and TF1 cells transfected with different amounts of PB-PIGA-wt (blue) or PB-PIGA-M37 (red).

translation downstream of this insertion resulting in a truncated PIGA protein starting at the methionine 37.

Additional evidence for the hypomorphic activity of an $\mathrm{N}$-terminal shorter protein comes from the initial cloning of mouse Piga [Kawagoe et al., 1994]. The group of Kinoshita first isolated a so-called 'truncated cDNA' with an open reading frame that started at the second Methionine (Met) located at position AA 37 of the current protein. After transfection of this truncated cDNA in BW5147 Thy $-1^{-}$cells, complementation of Thy- 1 expression was only partially obtained. Therefore, they extended the $5^{\prime}$ end to get the fulllength cDNA revealing a much higher Thy- 1 expression. Secondly, frameshift or nonsense mutations that affect the first 36 amino acids have not been described in PNH patients. The reported p. R19W missense variant is a known polymorphism (rs34422225) [Nafa et al., 1998], while the contribution of the p.I35K variant to $\mathrm{PNH}$ is highly doubtful because of the concurrent splice site mutation resulting in deletion of exon 4 in this patient [Yamada et al., 1995]. Therefore, we hypothesize that nonsense or frameshift mutations that affect the first $36 \mathrm{AA}$ are less likely to result in PNH because of sufficient residual activity of the alternative M37 form. Functional validation of this hypothesis however, is required.

As a general rule the AUG closest to the $5^{\prime}$ end of the mRNA transcript is being used as the translation start, which is known as the scanning mechanism [Kozak, 2002]. However, context-dependent leaky scanning and reinitiation of translation are well-known mechanisms to escape this first-ATG rule. Since reinitiation of translation is a rather inefficient process [Kozak, 2002], the amounts of hypomorphic PIGA that are expected to be produced in our patient are lower than the wild-type levels. However, these reduced amounts, if any, do not seem to affect GPI-AP cell surface expression. We were unable to assess the amounts or the molecular weight of PIGA in our patient because of the unavailability of a decent antibody. A similar reinitiation event was suspected for a missense mutation (p.M1L) that abrogated the start codon of SLC16A2/MCT8, which should lead to the severe Allan-Herdon-Dudley syndrome (AHDS; MIM \#300523). This variant was identified in a male ID patient without AHDS as well as in healthy male family members. Measurement of T3 levels also demonstrated normal functional activity of 
this protein strongly suggesting that an alternative ATG was used as the translation start though no formal proof was provided for that [Frints et al., 2008].

In conclusion, in our XLID family, we suggest the production of a hypomorphic-truncated PIGA protein produced by reinitiation of translation due to an early frameshift mutation. The residual activity of the apparent truncated PIGA is sufficient to survive into adulthood but not to rescue the MCAHS2-like associated features. Moreover, our data demonstrate that mutations in proteins that play a role early in the GPI anchor biosynthesis do not always result in a more severe clinical outcome when compared with those in proteins with functions later in this pathway as has been suggested recently [Hansen et al., 2013]. Very recently, two studies report on two novel germline mutations in PIGA (c.278C > T: p.P93L; and c.328_330delCCT: p.L344del) in male patients with clinical features partially overlapping those of MCAHS2 providing further evidence for a broader clinical spectrum [Swoboda et al., 2013; van der Crabben et al., 2013]. The additional presence of hypsarrhythmia, diagnosed in all five affected males of this family, could be a discriminating feature for hypomorphic PIGA mutations.

\section{Acknowledgments}

The authors thank the L024 family members for their willingness to contribute to this research project. We also thank Melanie Bienek (Max Planck Institute for Molecular Genetics, Berlin) for excellent technical assistance.

N.F. is a Ph.D. fellow from the IWT (Agentschap voor Innovatie door Wetenschap en Technologie), Belgium. H.V.E. is a clinical investigator of the Fund for Scientific Research (FWO) Vlaanderen.

Disclosure statement: The authors declare no conflict of interest.

\section{References}

Almeida AM, Murakami Y, Layton DM, Hillmen P, Sellick GS, Maeda Y, Richards S, Patterson S, Kotsianidis I, Mollica L, Crawford DH, Baker A, et al. 2006. Hypomorphic promoter mutation in PIGM causes inherited glycosylphosphatidylinositol deficiency. Nat Med 12:846-851.

Bessler M, Mason PJ, Hillmen P, Miyata T, Yamada N, Takeda J, Luzzatto L, Kinoshita T. 1994. Paroxysmal nocturnal haemoglobinuria (PNH) is caused by somatic mutations in the PIG-A gene. EMBO J 13:110-117.

Brodsky RA. 2008. Narrative review: paroxysmal nocturnal hemoglobinuria: the physiology of complement-related hemolytic anemia. Ann Intern Med 148:587-595.

Brodsky RA, Mukhina GL, Li S, Nelson KL, Chiurazzi PL, Buckley JT, Borowitz MJ. 2000. Improved detection and characterization of paroxysmal nocturnal hemoglobinuria using fluorescent aerolysin. Am J Clin Pathol 114:459-466.

Claes S, Devriendt K, Lagae L, Ceulemans B, Dom L, Casaer P, Raeymaekers P, Cassiman JJ, Fryns JP. 1997. The X-linked infantile spasms syndrome (MIM 308350) maps to Xp11.4-Xpter in two pedigrees. Ann Neurol 42:360-364.

de Brouwer AP, Yntema HG, Kleefstra T, Lugtenberg D, Oudakker AR, de Vries BB, van Bokhoven H, Van Esch H, Frints SG, Froyen G, Fryns JP, Raynaud M, et al. 2007. Mutation frequencies of X-linked mental retardation genes in families from the EuroMRX consortium. Hum Mutat 28:207-208.

Frints SG, Lenzner S, Bauters M, Jensen LR, Van Esch H, des Portes V, Moog U, Macville MV, van Roozendaal K, Schrander-Stumpel CT, Tzschach A, Marynen P, et al. 2008. MCT8 mutation analysis and identification of the first female with AllanHerndon-Dudley syndrome due to loss of MCT8 expression. Eur J Hum Genet 16:1029-1037.

Fujita M, Kinoshita T. 2012. GPI-anchor remodeling: potential functions of GPIanchors in intracellular trafficking and membrane dynamics. Biochim Biophys Acta 1821:1050-1058.

Gécz J, Shoubridge C, Corbett M. 2009. The genetic landscape of intellectual disability arising from chromosome X. Trends Genet 25:308-316.

Hansen L, Tawamie H, Murakami Y, Mang Y, ur Rehman S, Buchert R, Schaffer S, Muhammad S, Bak M, Nothen MM, Bennett EP, Maeda Y, et al. 2013. Hypomorphic mutations in PGAP2, encoding a GPI-anchor-remodeling protein, cause autosomal-recessive intellectual disability. Am J Hum Genet 92:575-583.

Johnson RJ, Hillmen P. 2002. Paroxysmal nocturnal haemoglobinuria: nature's gene therapy? Mol Pathol 55:145-152.

Johnston JJ, Gropman AL, Sapp JC, Teer JK, Martin JM, Liu CF, Yuan X, Ye Z, Cheng L, Brodsky RA, Biesecker LG. 2012. The phenotype of a germline mutation in
PIGA: the gene somatically mutated in paroxysmal nocturnal hemoglobinuria. Am J Hum Genet 90:295-300.

Kawagoe K, Kitamura D, Okabe M, Taniuchi I, Ikawa M, Watanabe T, Kinoshita T, Takeda J. 1996. Glycosylphosphatidylinositol-anchor-deficient mice: implications for clonal dominance of mutant cells in paroxysmal nocturnal hemoglobinuria. Blood 87:3600-3606.

Kawagoe K, Takeda J, Endo Y, Kinoshita T. 1994. Molecular cloning of murine pig-a, a gene for GPI-anchor biosynthesis, and demonstration of interspecies conservation of its structure, function, and genetic locus. Genomics 23:566-574.

Keller P, Tremml G, Rosti V, Bessler M. 1999. X inactivation and somatic cell selection rescue female mice carrying a Piga-null mutation. Proc Natl Acad Sci USA 96:74797483.

Kozak M. 2002. Pushing the limits of the scanning mechanism for initiation of translation. Gene 299:1-34.

Krawitz PM, Murakami Y, Hecht J, Kruger U, Holder SE, Mortier GR, Delle CB, De Baere E, Thompson MD, Roscioli T, Kielbasa S, Kinoshita T, et al. 2012. Mutations in PIGO, a member of the GPI-anchor-synthesis pathway, cause hyperphosphatasia with mental retardation. Am J Hum Genet 91:146-151.

Krawitz PM, Murakami Y, Riess A, Hietala M, Kruger U, Zhu N, Kinoshita T, Mundlos S, Hecht J, Robinson PN, Horn D. 2013. PGAP2 mutations, affecting the GPI-anchorsynthesis pathway, cause hyperphosphatasia with mental retardation syndrome. Am J Hum Genet 92:584-589.

Krawitz PM, Schweiger MR, Rodelsperger C, Marcelis C, Kolsch U, Meisel C, Stephani F, Kinoshita T, Murakami Y, Bauer S, Isau M, Fischer A, et al. 2010. Identity-bydescent filtering of exome sequence data identifies PIGV mutations in hyperphosphatasia mental retardation syndrome. Nat Genet 42:827-829.

Maydan G, Noyman I, Har-Zahav A, Neriah ZB, Pasmanik-Chor M, Yeheskel A, binKaplanski A, Maya I, Magal N, Birk E, Simon AJ, Halevy A, et al. 2011. Multiple congenital anomalies-hypotonia-seizures syndrome is caused by a mutation in PIGN. J Med Genet 48:383-389.

Nafa K, Bessler M, Castro-Malaspina H, Jhanwar S, Luzzatto L. 1998. The spectrum of somatic mutations in the PIG-A gene in paroxysmal nocturnal hemoglobinuria includes large deletions and small duplications. Blood Cells Mol Dis 24:370384.

Ng BG, Hackmann K, Jones MA, Eroshkin AM, He P, Wiliams R, Bhide S, Cantagrel V, Gleeson JG, Paller AS, Schnur RE, Tinschert S, et al. 2012. Mutations in the glycosylphosphatidylinositol gene PIGL cause CHIME syndrome. Am J Hum Genet 90:685-688.

Ropers HH. 2010. Genetics of early onset cognitive impairment. Annu Rev Genomics Hum Genet 11:161-187.

Rosse WF. 1993. Evolution of clinical understanding: paroxysmal nocturnal hemoglobinuria as a paradigm. Am J Hematol 42:122-126.

Savage WJ, Barber JP, Mukhina GL, Hu R, Chen G, Matsui W, Thoburn C, Hess AD, Cheng L, Jones RJ, Brodsky RA. 2009. Glycosylphosphatidylinositol-anchored protein deficiency confers resistance to apoptosis in PNH. Exp Hematol 37:42-51.

Sutherland DR, Kuek N, zcona-Olivera J, Anderson T, Acton E, Barth D, Keeney M. 2009. Use of a FLAER-based WBC assay in the primary screening of PNH clones. Am J Clin Pathol 132:564-572.

Swoboda KJ, Margraf RL, Carey JC, Zhou H, Newcomb TM, Coonrod E, Durtschi J, Mallempati K, Kumanovics A, Katz BE, Voelkerding KV, Opitz JM. 2013. A novel germline PIGA mutation in Ferro-Cerebro-Cutaneous syndrome: a neurodegenerative X-linked epileptic encephalopathy with systemic iron-overload. Am J Med Genet A 164:17-28.

Takeda J, Miyata T, Kawagoe K, Iida Y, Endo Y, Fujita T, Takahashi M, Kitani T, Kinoshita T. 1993. Deficiency of the GPI anchor caused by a somatic mutation of the PIG-A gene in paroxysmal nocturnal hemoglobinuria. Cell 73:703711.

van der Crabben SN, Harakalova M, Brilstra EH, van Berkestijn FM, Hofstede FC, van Vught AJ, Cuppen E, Kloosterman W, Ploos van Amstel HK, van HG, van Haelst MM. 2013. Expanding the spectrum of phenotypes associated with germline PIGA mutations: a child with developmental delay, accelerated linear growth, facial dysmorphisms, elevated alkaline phosphatase, and progressive CNS abnormalities. Am J Med Genet A 164:29-35.

Vandewalle J, Van Esch H, Govaerts K, Verbeeck J, Zweier C, Madrigal I, Mila M, Pijkels E, Fernandez I, Kohlhase J, Spaich C, Rauch A et al. 2009. Dosage-dependent severity of the phenotype in patients with mental retardation due to a recurrent copy-number gain at Xq28 mediated by an unusual recombination. Am J Hum Genet 85:809-822.

Yamada N, Miyata T, Maeda K, Kitani T, Takeda J, Kinoshita T. 1995. Somatic mutations of the PIG-A gene found in Japanese patients with paroxysmal nocturnal hemoglobinuria. Blood 85:885-892.

Yusa K, Zhou L, Li MA, Bradley A, Craig NL. 2011. A hyperactive piggyBac transposase for mammalian applications. Proc Natl Acad Sci USA 108:1531-1536.

Zou C, Chou BK, Dowey SN, Tsang K, Huang X, Liu CF, Smith C, Yen J, Mali P, Zhang YA, Cheng L, Ye Z. 2012. Efficient derivation and genetic modifications of human pluripotent stem cells on engineered human feeder cell lines. Stem Cells Dev 21:2298-2311. 